\title{
A Silsesquioxane Organically Modified with 4-Amino-5-(4-pyridyl)-4H-1,2,4-triazole-3-thiol: Thermal Behavior and Its Electrochemical Detection of Sulfhydryl Compounds
}

\author{
D. R. Do Carmo, ${ }^{1}$ D. R. Silvestrini, ${ }^{1}$ H. S. Barud, ${ }^{2}$ N. L. Dias Filho, ${ }^{1}$ \\ U. O. Bicalho, ${ }^{1}$ and L. A. Soares ${ }^{1}$ \\ ${ }^{1}$ Faculdade de Engenharia de Ilha Solteira, Universidade Estadual Paulista (UNESP), Departamento de Física e Química, \\ Avenida Brasil Centro 56, 15385-000 Ilha Solteira, SP, Brazil \\ ${ }^{2}$ Instituto de Química de Araraquara, Universidade Estadual Paulista (UNESP), Departamento de Físico Química, \\ Rua Professor Francisco Degni 55, 14800-060 Araraquara, SP, Brazil
}

Correspondence should be addressed to D. R. Do Carmo; docarmo@dfq.feis.unesp.br

Received 21 December 2013; Revised 15 May 2014; Accepted 18 May 2014; Published 9 July 2014

Academic Editor: Bin Zhang

Copyright (C) 2014 D. R. Do Carmo et al. This is an open access article distributed under the Creative Commons Attribution License, which permits unrestricted use, distribution, and reproduction in any medium, provided the original work is properly cited.

\begin{abstract}
The octakis(3-chloropropyl)silsesquioxane (SS) was organofunctionalized with 4-amino-5-4(pyridyl)-4H-1,2,4-triazole-3-thiol. The product formed (SA) was undergo another reactions in two steps, first with copper and so hexacyanoferrate (III) to form CuHSA. The organofunctionalized silsesquioxane was characterized by the following techniques: scanning electron microscopy (SEM), Fourier transform infrared (FTIR), nuclear magnetic resonance (NMR) in solid state, and thermogravimetric analysis in air and nitrogen atmosphere. The composite CuHSA was incorporated into a graphite paste electrode and the electrochemical behavior studies were conducted with cyclic voltammetry. The cyclic voltammogram of the modified graphite paste electrode with CuHSA showed one redox couple with formal potential $E^{\theta^{\prime}}=0.75 \mathrm{~V}$ versus $\mathrm{Ag} / \mathrm{AgCl}_{\text {(sat) }}\left(\mathrm{KCl} 1.0 \mathrm{~mol} \mathrm{~L} \mathrm{~L}^{-1} ; v=20 \mathrm{mV} \mathrm{s}^{-1}\right)$ attributed to the redox process $\mathrm{Fe}^{(\mathrm{II})}(\mathrm{CN})_{6} / \mathrm{Fe}^{(\mathrm{III})}(\mathrm{CN})_{6}$ of the binuclear complex formed. The redox couple presents an electrocatalytic response of sulfhydryl compounds such as n-acetylcysteine and l-cysteine. For determination of n-acetylcysteine and l-cysteine the modified graphite paste electrode showed a linear region in the concentration range of 2 to $20 \mathrm{mmol} \mathrm{L}^{-1}$. The modified electrode was chemically and electrochemically stable and showed good reproducibility.
\end{abstract}

\section{Introduction}

In recent years, the development of hybrid materials has been the subject of considerable attention of the scientific community due to their organic and inorganic moieties working together to give the hybrid different properties from those displayed in their precursors [1]. Currently, there is great interest in the formation of hybrid materials by incorporating organic groups into structures of silsesquioxanes [2]. Hybrid organic/inorganic composites from silsesquioxanes, nanostructured compounds with an empirical formula $\left(\mathrm{RSiO}_{1.5}\right) n$, where $\mathrm{R}$ is a hydrogen atom or an organic group [3] and $n=$ $4,6,8,10(n \geq 4)$ [4], have wide applications, for instance, as catalysts $[5,6]$, liquid crystals $[7,8]$, nanofillers [9], sensors and biosensors $[10,11]$, silica interface $[12,13]$, medicine [14, $15]$, and dendrimer precursors $[14,16]$.

Recently several reviews and extensive papers about synthesis, reactions, and applications about silsesquioxanes were reported $[4,17]$.

When functionalized, silsesquioxane can improve some of their properties without affecting their characteristics, for example, mechanical and thermal properties $[18-20]$ and also their oxidation resistance [17].

Metal coordination with silsesquioxane is only common when using incompletely condensed silsesquioxanes such as trisilanol and polyhedral oligomeric silsesquioxane (POSS). 
These nanostructured materials are capable of mimicking the main characteristics of the inorganofuctionalized silica with different metals [14, 21-24].

In the literature some papers on hybrid and soluble silsesquioxanes with defined and undefined structures containing charged organic group were already reported, dealing with the development of electrochemical sensors [11, 25]. To the best of our knowledge, the electroanalytical applications of chemically modifiedcubic silsesquioxane have been only mentioned by Do Carmo research group [26, 27].

In this paper we present the preparation, characterization, and voltammetric study of copper hexacyanoferrate (CuHCF) obtained by the interaction with the functionalized cubic polyhedral oligosilsesquioxane (SS) and 4-amino-5(4-pyridyl)-4H-1,2,4-triazole-3-thiol (APTT) (SA) in two stages. At the first stage, the SA adsorbs $\mathrm{Cu}^{2+}$ and at the second step the composite formed (CuSA) reacts with hexacyanoferrate forming a new composite (CuHSA). After rigorous voltammetric studies, the composite was tested in the electrocatalytic determination of sulphydrilic compounds such as l-cysteine and n-acetylcysteine. APTT was chosen because presents in your structure nitrogen and sulfur sites can bind different transition metals [28]. Therefore, APTT is a power ligand for organofunctionalization and sorption of metals. Sulfhydryl compounds cannot be determined directly with glassy carbon electrodes, platinum electrodes, and gold electrodes, but rather with mercury-based electrodes, with the latter due to the strong Hg-S interaction [29].

However, currently the use of mercury-based electrodes in analytical chemistry is strongly discouraged because of its toxic nature, which encourages researchers to create a "cleaner" detection strategy using electrodes.

The detection of the aforementioned compounds is usually performed by chromatographic or spectrophotometric techniques. These methods are accurate, sensitive, and selective but are lengthy processes as they require derivatization and separation processes and require using relatively expensive devices. This has aroused interest in their detection and quantification by electroanalytical techniques, given that, in addition to being simple to use and low cost, they offer the possibility of determining the analyte concentration directly in the sample without pretreatment or chemical separation [30-32].

One of the most important and recent advances in the preparation of new electrodic materials was incorporating nanotechnology to the construction processes of electrochemical sensors, which could contribute significantly to the quantification of species of environmental interest, such as pesticide residues, dyes, and heavy metals and also for the quality control of inputs from the pharmaceutical and food industries. Electrodes containing nanostructured materials are carbon nanotubes $[33,34]$, nanoparticles, and nanocapsules $[35,36]$, besides several types of electrodes with nanometer porosity obtained by different methods [37-40] and which have brought impressive advances to voltammetric methods, especially those based on stripping voltammetric techniques since nanostructured materials exhibit a number of advantageous properties, such as high surface area which allows greater preconcentration capacity of the analyte, providing strong adsorptive capacity and low detection limits. The advantages of using POSS, compared with other nanostructured compounds, such as carbon nanotubes, regard their smaller size and that they are easily modified chemically to suit a particular application [4].

Thus, the chemically modified silsesquioxanes are excellent candidates for electrocatalytic reduction or oxidation of both organic and inorganic analytes, greatly contributing to the field of electroanalysis.

\section{Experimental}

2.1. Reagents. All reagents and solvents were of analytical grade (Alpha Aesar, Merck, or Aldrich) and were used as purchased. Deionized water was produced with Milli-Q gradient system from Millipore.

\subsection{Techniques}

2.2.1. Microscopy. The scanning electronic microscopy of the materials was obtained using a JEOL JSM T-300 microscope. The samples were adhered over aluminum holders and covered with a thin layer $(20-30 \mathrm{~nm})$ of gold in Sputter Coater Bal-Tec SCD-050.

2.2.2. Nuclear Magnetic Resonance Analyses (NMR). All solid state analyses of ${ }^{29} \mathrm{Si}(59.5 \mathrm{MHz})$ and ${ }^{13} \mathrm{C}-\mathrm{NMR}(75.4 \mathrm{MHz})$ were recorded on a Varian INOVA 300 spectrometer. The samples were packed in zirconia rotors and spun at the magic angle at $4500 \mathrm{~Hz}$, a relaxation delay of 10.0 and $6.0 \mathrm{~s}$ for ${ }^{29} \mathrm{Si}$ and ${ }^{13} \mathrm{C}$, respectively. All chemical shifts are reported in parts per million ppm $(\delta)$ with reference to external tetramethylsilane (TMS).

2.2.3. Thermogravimetric Analysis (TG-DTA). The thermogravimetric analyses of the samples were carried out using two types of equipment-SDT 2960 from TA Instruments and SDT Q600 from TA Instruments.

The thermogravimetric curves were obtained using approximately $6 \mathrm{mg}$ samples placed in alumina crucibles and subjected to a controlled air temperature program and nitrogen flow of $100 \mathrm{~mL} \mathrm{~min}^{-1}$, with a heating rate of $10^{\circ} \mathrm{C} \mathrm{min}^{-1}$. The sample analyses were performed at the room temperature interval up to $1200^{\circ} \mathrm{C}$. As $\mathrm{S}$ contains chlorine in its composition, it releases chlorine gas when heated, which reacts with the crucible; therefore it was subjected to heating at a temperature of $700^{\circ} \mathrm{C}$.

2.2.4. Preparation of Chemically Modified Graphite Paste Electrodes. The chemically modified graphite paste electrodes were prepared by mixing the modified silsesquioxane (CuHSA, $20 \mathrm{mg}$ ), graphite powder $(80 \mathrm{mg})$, and nujol oil as a agglutinative $(25 \mu \mathrm{L})$. Graphite, CuHSA, and nujol were mixed to produce a homogeneous graphite modified paste electrode. The electrode body was fabricated from a glass tube of i.d. $3 \mathrm{~mm}$ and height of $14 \mathrm{~cm}$, containing graphite paste [42]. A copper wire was inserted through the opposite end to establish electrical contact. After the mixture had been homogenized, the modified paste was carefully positioned on 


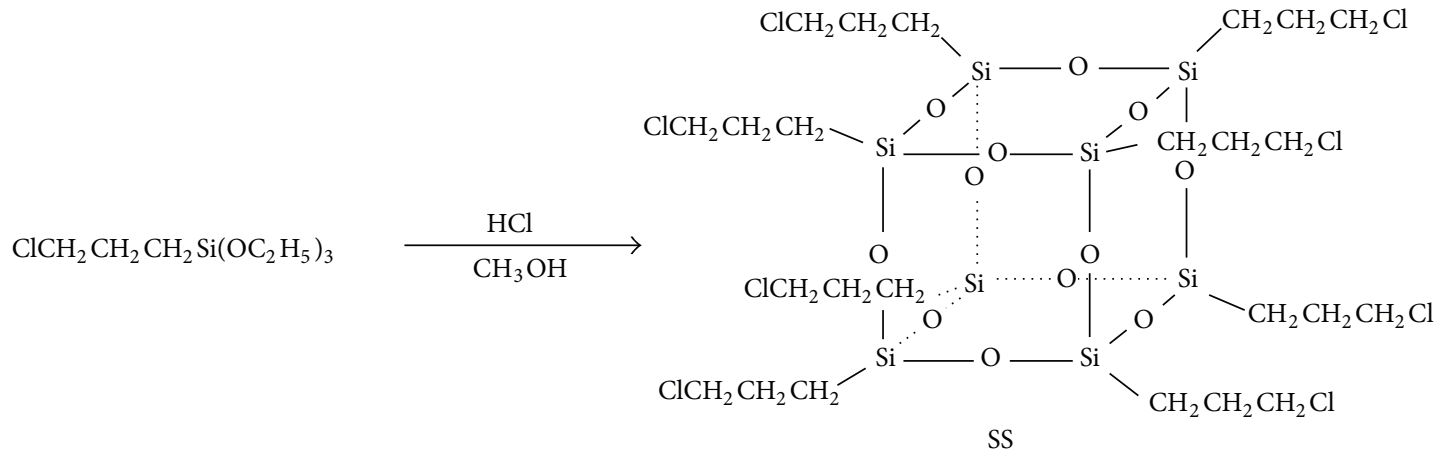

(a)<smiles>[R17]CC[Si]12O[Si]3(CCCCl)O[Si]4(CCCCl)O[Si](CCCCl)(O1)O[Si]1(CCCCl)O[Si](CCCCl)(O2)O[Si](CCCCl)(O3)O[Si](CCCCl)(O4)O1</smiles>

SA<smiles>[R]=C=[W]=[Pt]Nn1c(S)nnc1-c1ccncc1</smiles><smiles>[R]CCC[Si]1(O)O[Si]2(CC[R])O[Si](CC[R])(O1)O[Si]1(CCC[R])O[Si]3(CC[R])O[Si](CC[R])(O2)O[Si](CCC[R])(O1)O3</smiles>

SS

(b)

FIGURE 1: (a) Preparation of octakis(3-chloropropyl)silsesquioxane and (b) organofunctionalization of octakis(3-chloropropyl)silsesquioxane (SS) with the modifying agent APTT [41].

the tube tip to avoid possible air gaps, which often enhances electrode resistance. The external surface of the electrode was smoothed on soft paper. A new surface can be produced by scraping out the old surface and replacing the graphite paste.

2.2.5. Analysis Procedure. Initially, cyclic voltammograms were recorded for studying the electro-oxidation of l-cysteine and $n$-acetylcysteine by graphite paste electrode modified with CuHSA. The l-cysteine and n-acetylcysteine solutions were prepared immediately before use and were purged with nitrogen. In most of the experiments, $1.0 \mathrm{~mol} \mathrm{~L}^{-1} \mathrm{KCl}(\mathrm{pH} \sim$ 6.8) was used as the supporting electrolyte. The catalytic current was estimated by the difference between the electrode current in the presence of sulfhydryl compounds and that which is established in the blank solution.

\subsection{Synthesis}

2.3.1. Synthesis of Octakis(3-chloropropyl)silsesquioxane (SS). For the synthesis of octakis(3-chloropropyl)silsesquioxane (SS) a procedure described in the literature was followed [43]. $800 \mathrm{~mL}$ of methanol, $27.0 \mathrm{~mL}$ of hydrochloric acid $(\mathrm{HCl})$, and
$43.0 \mathrm{~mL}$ of 3-chloropropyltrimethoxysilane were added into a $1000 \mathrm{~mL}$ round bottom flask. The reaction was stirred at room temperature for 5 weeks. The solid phase was separated by filtration in a sintered plate funnel; it yielded a white solid which was then oven dried at $120^{\circ} \mathrm{C}$ for 4 hours (Figure 1(a)).

2.3.2. Functionalization of Octakis(3-chloropropyl)silsesquioxane with APTT (SA). The functionalization of octakis(3-chloropropyl)silsesquioxane (SS) (Figure 1(b)) was performed in $500 \mathrm{~mL} 3$-neck flask containing $9.70 \times 10^{-3} \mathrm{~mol}(10.05 \mathrm{~g})$ of $\mathrm{SS}$, previously dried at $100^{\circ} \mathrm{C}$ for $2 \mathrm{~h}, 8.70 \times 10^{-2} \mathrm{~mol}(16.81 \mathrm{~g})$ of APTT, and approximately $200 \mathrm{~mL}$ of dimethylformamide (DMF). The mixture was refluxed at $150^{\circ} \mathrm{C}$ with constant stirring for 96 hours. Then the solid phase was separated in a sintered funnel and washed in a Soxhlet extractor with DMF for 48 hours. The material obtained was oven vacuum dried at $100^{\circ} \mathrm{C}$ for 4 hours (Figure 1(b)).

2.3.3. Preparation of Copper Hexacyanoferrate with SA (CuHSA). The complexes were prepared as follows: $1.0 \mathrm{~g}$ of SA was added to $25 \mathrm{~mL}$ of a solution of $1.0 \times 10^{-3} \mathrm{~mol} \mathrm{~L}^{-1}$ 

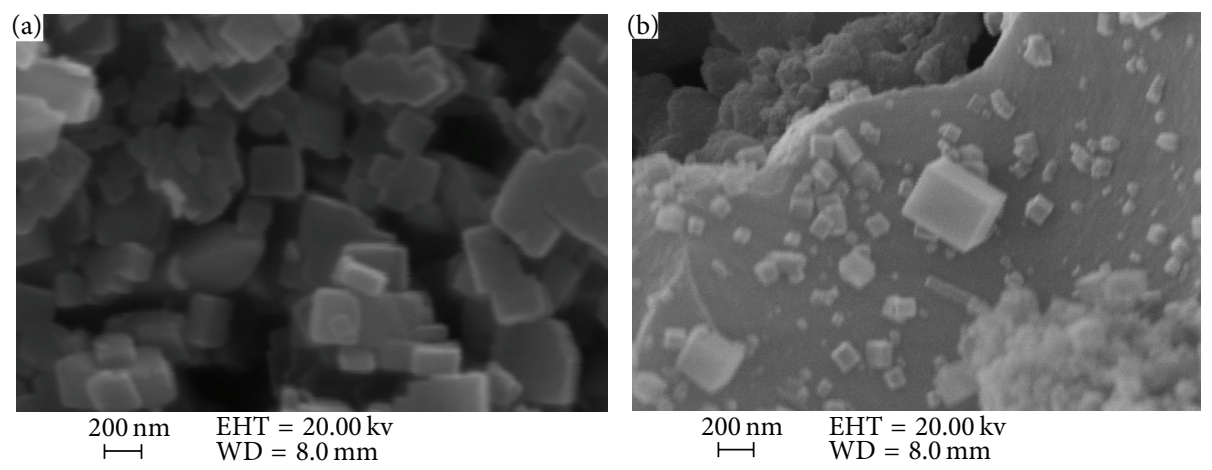

Figure 2: SEM of (a) SS and (b) CuHSA.

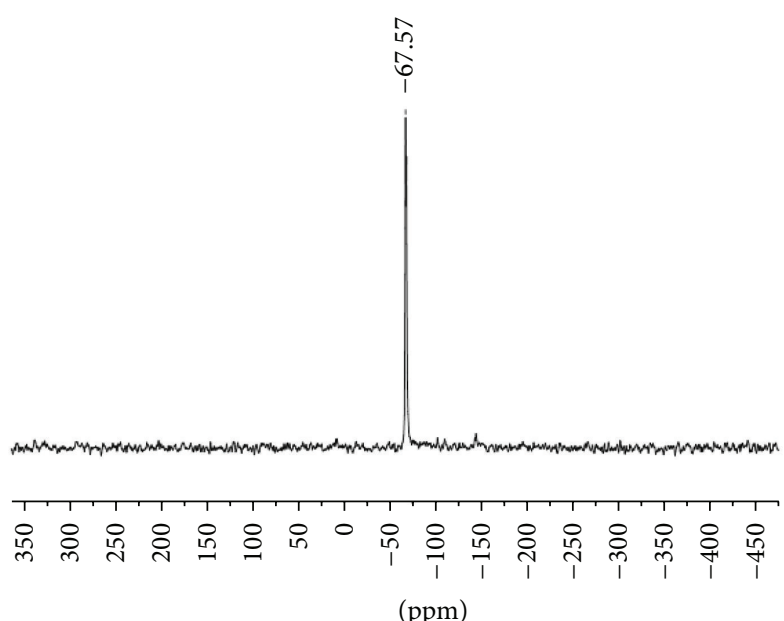

(a)

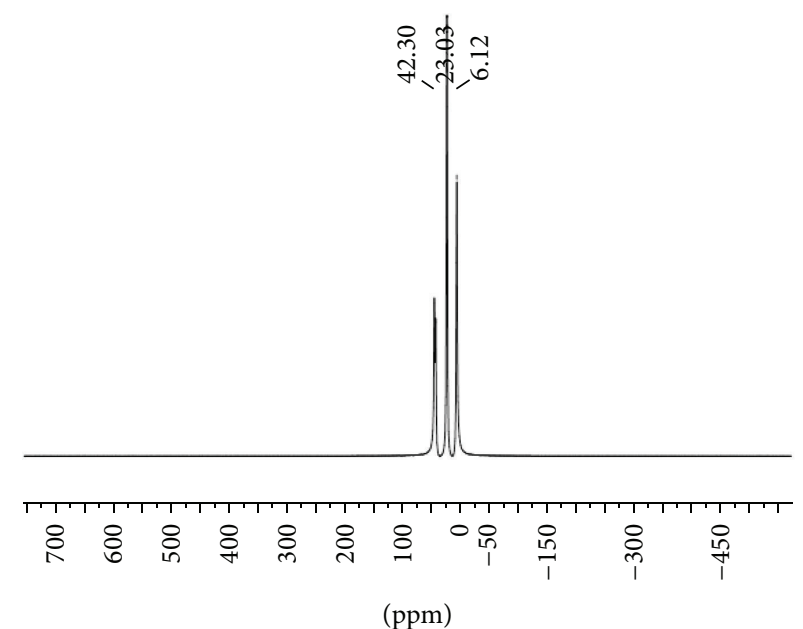

(b)

FIGURE 3: NMR: (a) ${ }^{29} \mathrm{Si}$ and (b) ${ }^{13} \mathrm{C}$ spectrum in the solid state for SS.

$\mathrm{CuCl}_{2} \cdot 5 \mathrm{H}_{2} \mathrm{O}$. The mixture was stirred for 40 minutes at room temperature. The solid phase was then filtered and washed thoroughly with deionized water. The materials resulting from this first phase were oven dried at $70^{\circ} \mathrm{C}$ and designated as CuSA. In the second stage, the CuSA was added to a solution of $1.0 \times 10^{-3} \mathrm{~mol} \mathrm{~L}^{-1}$ of potassium hexacyanoferrate (III) $\left(\mathrm{K}_{3}\left[\mathrm{Fe}(\mathrm{CN})_{6}\right]\right)$ and the mixture was stirred for 40 minutes at room temperature and then the solid was thoroughly filtered, washed with deionized water, and dried at room temperature. The materials resulting from this stage were described by CuHSA.

\section{Results and Discussion}

3.1. Scanning Electron Microscopy (SEM). The morphology was characterized by scanning electron microscopy (SEM; Figure 2). The images show irregular polyhedra or nanocubes (cubic particles) with an average size of 200 at $50 \mathrm{~nm}$ to SS and CuHSA materials, as illustrated in Figures 2(a) and 2(b), respectively. As can be seen there is a relatively high homogeny in cubic particle size and distributions both to SS and CuHSA. The size of the particles shapes decreased with the SS modification to form SA.
In the SEM of CuHSA minor particles shapes were noticeable. An investigation by SEM showed that the particles of CuHSA minor in size show irregular polyhedra or nanocubes.

3.2. Nuclear Magnetic Resonance (NMR). The FTIR spectrum of the APTT, SS, and one formed by reaction of SS with APTT (SA) and CuHSA was detailed in recent reports [27, 41]. In these studies, an absence of the band at $590 \mathrm{~cm}^{-1}$ related to the $\mathrm{C}-\mathrm{Cl}$ vibrations was observed as main spectral characteristic, therefore confirming the organofunctionalization of SA. The spectra of ${ }^{29} \mathrm{Si}$ and ${ }^{13} \mathrm{C} \mathrm{NMR}$ of octakis(3chloropropyl)silsesquioxane $\left[\mathrm{Cl}\left(\mathrm{CH}_{2}\right)_{3}\right]_{8} \mathrm{Si}_{8} \mathrm{O}_{12}(\mathrm{SS})$ are represented by Figures 3(a) and 3(b), respectively.

The spectrum of ${ }^{29} \mathrm{Si}$ NMR (Figure $3(\mathrm{a})$ ) of $\left[\mathrm{Cl}\left(\mathrm{CH}_{2}\right)_{3}\right]_{8}$. $\mathrm{Si}_{8} \mathrm{O}_{12}$ showed a resonance at $-67.57 \mathrm{ppm}$. This indicates the formation of the cubic structure of silsesquioxane with symmetrical $\mathrm{O}-\mathrm{Si}-\mathrm{O}$ bonds, as described in the literature [44-46].

The spectrum NMR ${ }^{13} \mathrm{C}$ (Figure 3(b)) shows three resonances attributed to three carbons of the propyl groups $(\alpha-6.12, \beta-23.03$, and $\gamma-42.30 \mathrm{ppm})$ and these carbons are identified as follows: $\alpha \mathrm{CH}_{2} \underline{\mathrm{CH}}_{2} \mathrm{Si}, \beta \mathrm{CH}_{2} \underline{\mathrm{CH}_{2}} \mathrm{CH}_{2}$, and $\gamma$ 


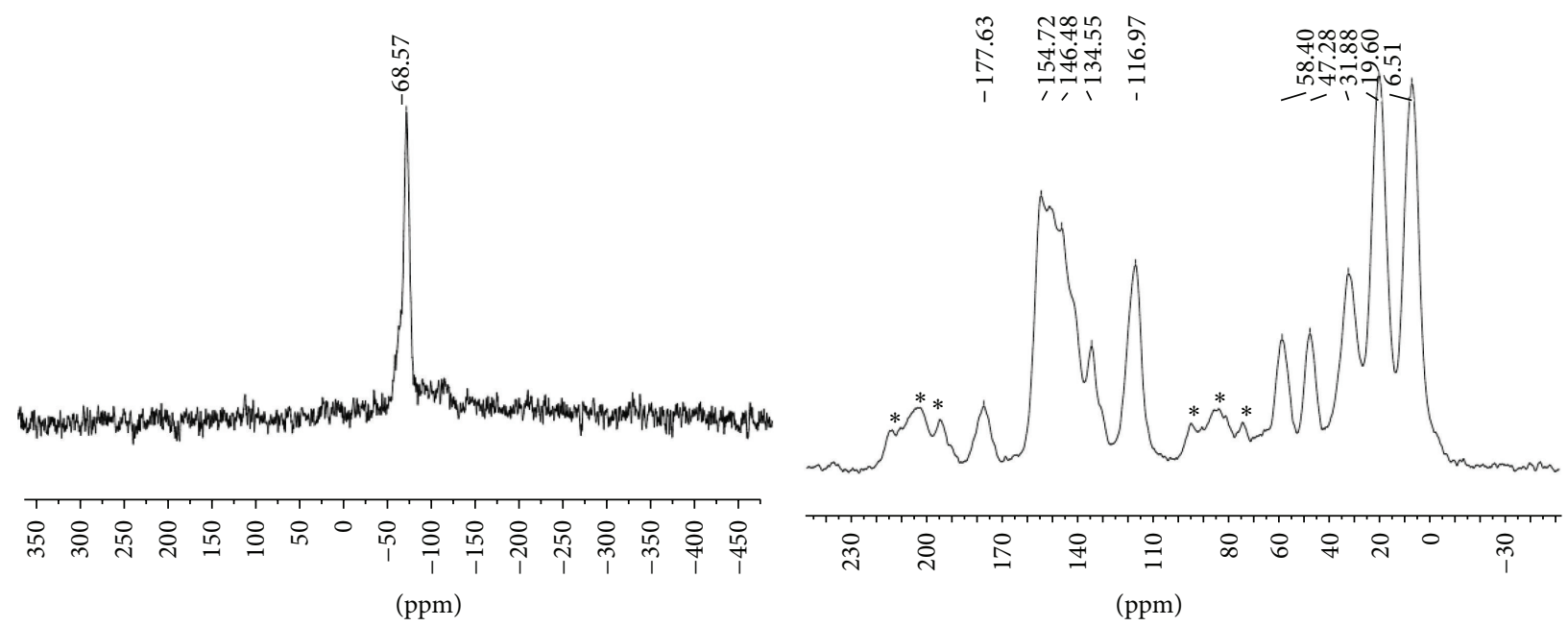

(a)

(b)

Figure 4: NMR: (a) ${ }^{29} \mathrm{Si}$ and (b) ${ }^{13} \mathrm{C}$ spectrum in the solid state for SA. * Side bands.

$\mathrm{ClCH}_{2} \mathrm{CH}_{2}$. These results clearly indicate the successful synthesis of octakis(3-chloropropyl)silsesquioxane [44-46].

The NMR ${ }^{29} \mathrm{Si}$ spectrum in the solid state for SA illustrated in Figure 4(a) shows only one resonance at $-68.57 \mathrm{ppm}$, which corresponds to silicon ( $\mathrm{Si}-\mathrm{O}-\mathrm{Si}$ ) [45, 46]. The ${ }^{29} \mathrm{Si} \mathrm{NMR}$ shows a large peak around $-68 \mathrm{ppm}$, which can be attributed to different environments of T3 species. In addition, the spectrum presents a shoulder around $-100 \mathrm{ppm}$ attributed to $\mathrm{Q}$ substructures, suggesting that the ligand alters the original structure of octakis(3-chloropropyl)silsesquioxane after functionalization.

The NMR of APTT ligand shows five resonance peaks as expected. Figure 4(b) illustrates the NMR ${ }^{13} \mathrm{C}$ spectrum in the solid state for SA. The resonance peaks observed at $6.51,19.60$, and $47.28 \mathrm{ppm}$ are attributed to the carbon atoms $\mathrm{CH}_{2} \mathrm{CH}_{2} \mathrm{Si}, \mathrm{CH}_{2} \mathrm{CH}_{2} \mathrm{CH}_{2}$, and $\mathrm{ClCH}_{2} \mathrm{CH}_{2}$ of the propyl group of precursor $\mathrm{SS}$ and the other resonances observed are attributed to the carbon atoms of the APTT ligand. The high levels of carbons observed for the APTT binder and the low frequencies are due to the chemical shift caused by the electronegative atoms attached to them and lack of $\mathrm{H}$ attached to their nuclei $[47,48]$. The results confirm that APTT was chemically bonded to the SS structure.

3.3. Thermogravimetric Analysis (TGA). The thermogravimetric curves indicate the thermal stability of the materials against a continuous programmed temperature heating rate [49].

The thermogram of SS (Figure 5(a)) showed three mass loss phases. In the first step at $100^{\circ} \mathrm{C}(1 \%)$ attributed to physically adsorbed water loss, confirmed by the endothermic event in the DTA curve; the other two mass loss stages were observed at $220^{\circ} \mathrm{C}(15 \%)$ and $320^{\circ} \mathrm{C}(33 \%)$ attributed to the oxidation of organic matter [50] and the decomposition of residual groups $\mathrm{SiO}_{2}[16,51,52]$ in the sample, also confirmed by the exothermic events in the DTA curve in the corresponding temperatures. It should be noted that as SS has chlorine in its composition, it was subjected to the programmed temperature increase up to the maximum temperature of $700^{\circ} \mathrm{C}$, because at high temperatures the chlorine gas released can react with the platinum crucible used in the measurements.

The thermogram of APTT (Figure 5(b)) showed four mass loss stages, the first at $100^{\circ} \mathrm{C}(1 \%)$ attributed to the physically adsorbed water loss and confirmed by the endothermic event in the DTA curve and three other stages at $200(7 \%)$, $350(60 \%)$, and $480^{\circ} \mathrm{C}(32 \%)$ all related to the oxidation of the organic part of the sample, confirmed by exothermic events in the DTA curve.

The thermogram of SA (Figure 5(c)) showed two mass loss stages, the first at $100^{\circ} \mathrm{C}(5 \%)$ attributed to the physically adsorbed water loss and confirmed by the endothermic event in the DTA curve at the corresponding temperature. It was observed that the anhydrous compound is stable up to temperatures close to $200^{\circ} \mathrm{C}$. At temperatures above $200^{\circ} \mathrm{C}$ the second mass loss stage was observed (65\%), attributed to oxidation of the organic matter in the sample and confirmed by the exothermic event in the DTA curve [50]; it was also observed that at temperatures above $800^{\circ} \mathrm{C}$ no further mass loss (total mass loss of 70\%) can be attributed to the formation of $\mathrm{SiO}_{2}$ formed by the oxidation of SA $[16,51,52]$.

The thermogram of SS in nitrogen atmosphere, illustrated in Figure 6(a), showed two mass loss stages. In the first stage at $100^{\circ} \mathrm{C}$ the mass loss was of $3 \%$, attributed to the release of physically adsorbed water on the silsesquioxane surface. It was observed that the material showed some stability at $200^{\circ} \mathrm{C}$ and the second mass loss stage occurred from 300 to $600^{\circ} \mathrm{C}$ (70\%), attributed to the degradation of the organic part in the sample.

The thermogram of APTT in nitrogen atmosphere, illustrated in Figure 6(b), showed three mass loss stages, the first at room temperature of $100^{\circ} \mathrm{C}(12 \%)$, attributed to the loss and release of physically adsorbed water and confirmed by the exothermic event in the DTA curve and two other stages at $200-500^{\circ} \mathrm{C}$ and $500-1200^{\circ} \mathrm{C}$ with a mass loss of $52 \%$. This 


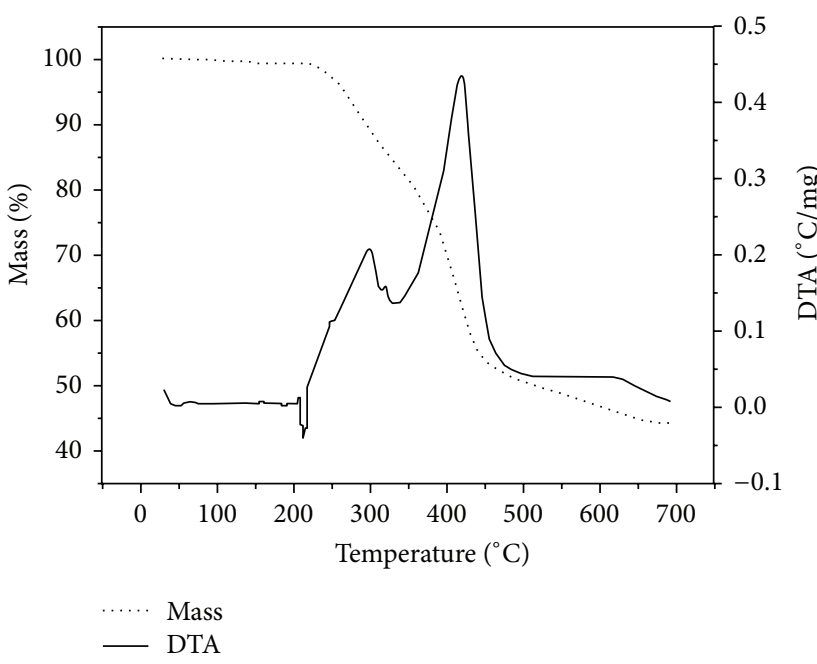

(a)

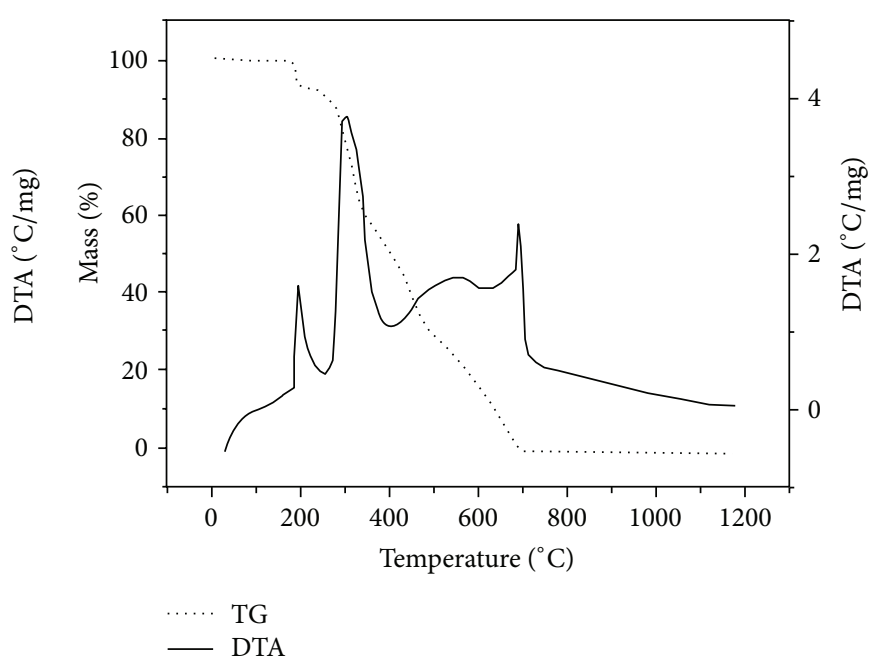

(b)

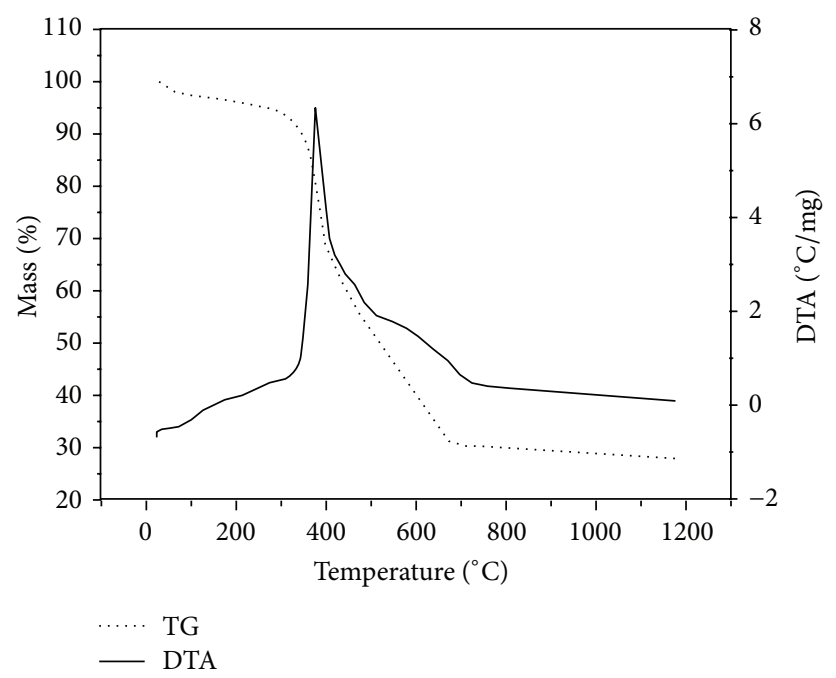

(c)

FIGURE 5: Thermogravimetric analysis in air atmosphere: (a) SS; (b) APTT; and (c) SA.

loss can be attributed to the degradation of organic matter in the sample.

The SA thermogram in nitrogen atmosphere, illustrated in Figure 6(c), exhibited two mass loss stages, the first at $100^{\circ} \mathrm{C}(5 \%)$, attributed to the physically adsorbed water loss. It was observed that the anhydrous compound is stable up to temperatures of around $200^{\circ} \mathrm{C}$. At temperatures of 200 to $800^{\circ} \mathrm{C}$ the second mass loss stage was observed $(55 \%)$, attributed to the degradation of organic matter in the sample. These mass loss stages were confirmed by the exothermic events of the DTA curve.

The thermogravimetric analysis studies showed that this new material (SA) showed relative thermal stability up to temperatures of around $250^{\circ} \mathrm{C}$, a common behavior in analogous compounds reported in the literature [50].

After reaction of SA with $\mathrm{Cu}$ and potassium hexacyanoferrate (III) (CuHSA), the composite was characterized by cyclic voltammetry. The cyclic voltammogram of the modified graphite paste electrode with CuHSA showed one redox couple with formal potential $E^{\theta^{\prime}}=0.75 \mathrm{~V}$ versus $\mathrm{Ag} / \mathrm{AgCl}_{\text {(sat) }}\left(\mathrm{KCl} 1.0 \mathrm{~mol} \mathrm{~L}^{-1} ; v=20 \mathrm{mV} \mathrm{s}^{-1}\right)$ attributed to the redox process $\mathrm{Fe}^{(\mathrm{II})}(\mathrm{CN})_{6} / \mathrm{Fe}^{(\mathrm{III})}(\mathrm{CN})_{6}$ of the binuclear complex formed [27].

\subsection{Application of Graphite Paste Electrode Modified with CuHSA}

3.4.1. Determination of $n$-Acetylcysteine and l-Cysteine. A substrate undergoing a redox process can exhibit slow electron transfer kinetics, but when this reaction is catalyzed by the modification of the electrode surface, there is a faster electron transfer between the electrode and the analyte [5355]; therefore, with the interaction between the modifier species in the electrode and analyte, there is an increase in the current intensity with the increasing addition of the analyte, which allows for the construction of a calibration curve for the detection and quantification of biologically significant substances [56]. 


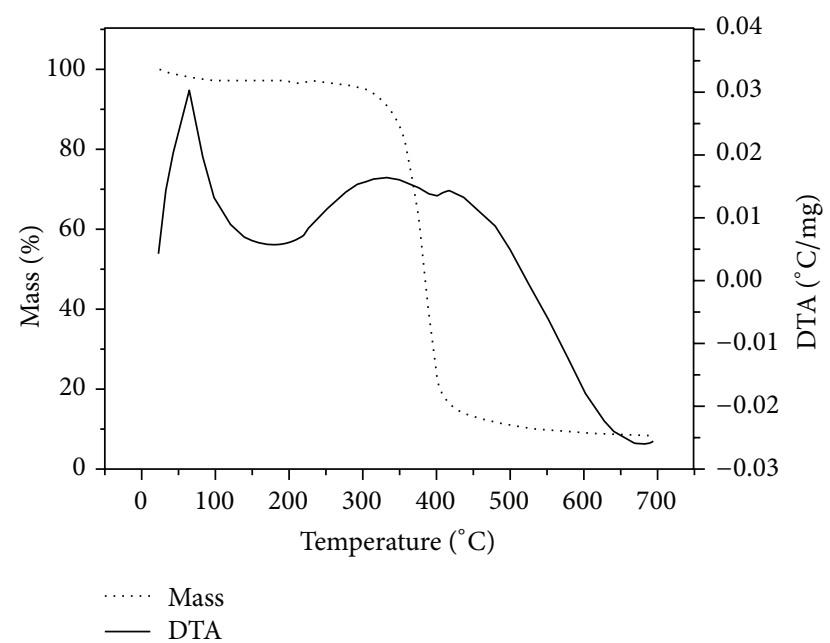

(a)

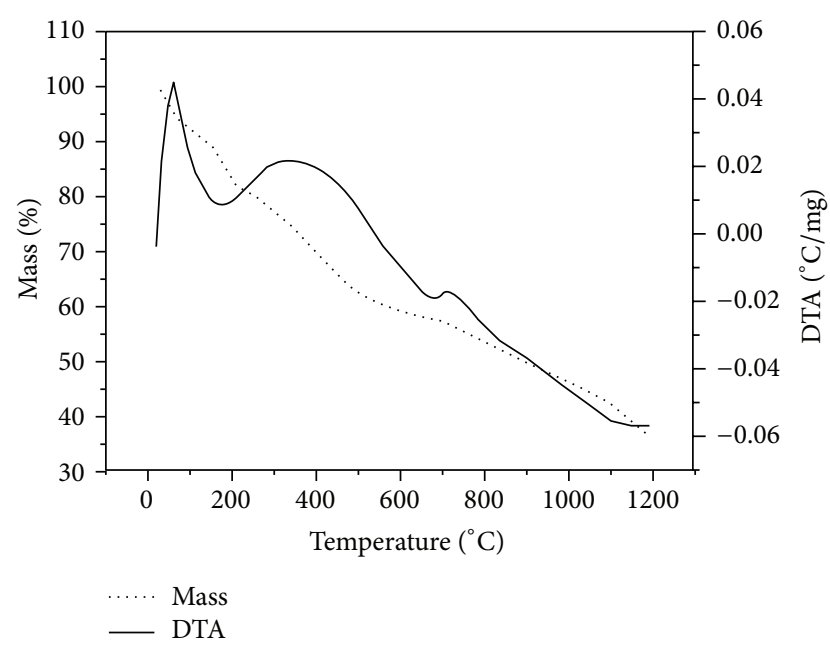

(b)

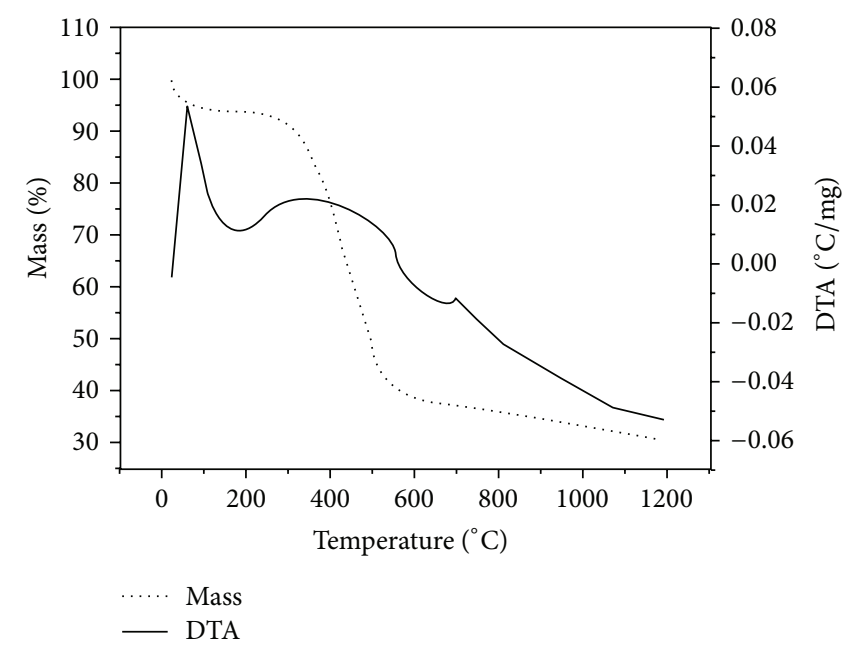

(c)

FIgURE 6: Thermogravimetric analysis in $\mathrm{N}_{2}$ atmosphere: (a) SS; (b) APTT; and (c) SA.

The analytical curve provides information on the detection limit and amperometric sensitivity of the method. The detection limit is defined as the lowest amount of analyte which can be detected in a sample [57] and is calculated by the following equation:

$$
\mathrm{LD}=\frac{\mathrm{SD} \times 3}{S}
$$

where SD is the standard deviation of ten measurements of white, at the very least three constructed standard curves containing proximate concentrations and the presumed limit of quantification, and $S$ (sensitivity) is the slope of the calibration curve [58]. The sensitivity $(S)$ of a method indicates its ability to discriminate, with a set accuracy, the proximate concentrations of an analyte. This magnitude can be determined by the slope of the calibration graph. In the case of a line, the greater the slope angle of the line, the more sensitive the method will be [59].
The electro-oxidation of the graphite paste electrode modified with CuHSA for the electro-oxidation of $\mathrm{n}$ acetylcysteine and l-cysteine in $1.0 \mathrm{~mol} \mathrm{~L}^{-1} \mathrm{KCl}$ is illustrated in Figures 7 and 8, respectively. According to Figure 7 the graphite paste electrode has no redox pair in the potential range between $0.4 \mathrm{~V}$ and 1.0 in the absence and presence of $\mathrm{n}$-acetylcysteine (curves $\mathrm{A}$ and $\mathrm{B}$, resp.). After the addition of $n$-acetylcysteine there was an increase in the anodic peak current intensity (curve D) when compared with the graphite paste electrode modified with CuHSA (curve C).

The intensity of the anodic peak current of CuHSA increases proportionately with the analyte concentration.

In the case of l-cysteine, the same process occurs, with a more pronounced electro-oxidation, as seen in Figure 8.

The equation for the electrochemical oxidation of 1cysteine, described in the literature [60] can be represented as follows:

$$
\text { 2l-Cysteine }(\mathrm{CySH}) \longrightarrow \text { Cystine }(\mathrm{CySSCy})+2 \mathrm{e}^{-}+2 \mathrm{H}^{+}
$$




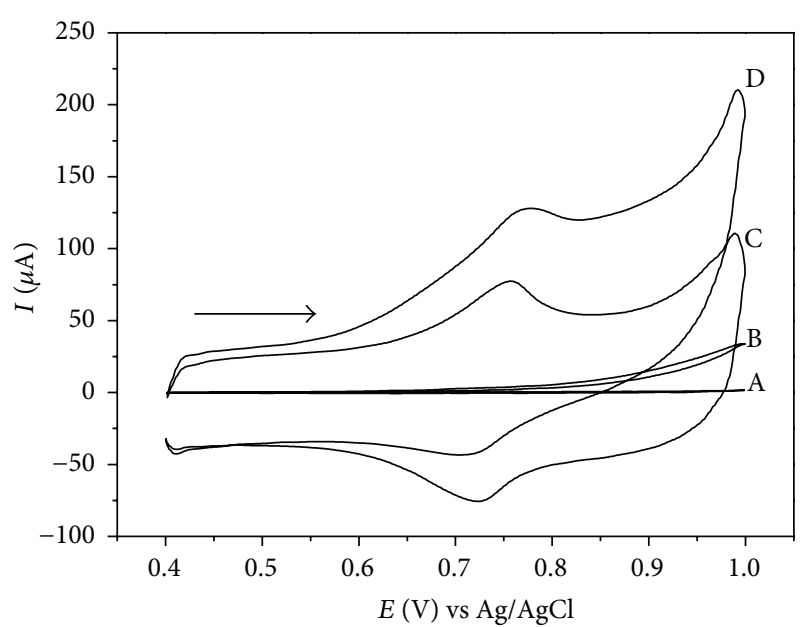

FIGURE 7: Cyclic voltammograms (A) of the graphite paste electrode; (B) of the graphite paste electrode and $9.0 \times 10^{-3} \mathrm{~mol} \mathrm{~L}^{-1}$ of $\mathrm{n}$ acetylcysteine; (C) of the graphite paste electrode modified with CuHSA; and (D) of the graphite paste electrode modified with CuHSA in $9.0 \times 10^{-3} \mathrm{~mol} \mathrm{~L}^{-1}$ of n-acetylcysteine $\left(\mathrm{KCl} 1.0 \mathrm{~mol} \mathrm{~L}^{-1}\right.$; $v=20 \mathrm{mV} \mathrm{s}^{-1}$; $\left.\mathrm{pH} 7.0 ; 20 \%(\mathrm{w} / \mathrm{w})\right)$.

This increased anodic current intensity occurs due to electrooxidation of the analytes (n-acetylcysteine and l-cysteine) by the mediator CuHSA. Fe(III) produced during the anodic scanning chemically oxidizes n-acetyl cysteine (l-cysteine), while this is reduced to $\mathrm{Fe}(\mathrm{II})$, which in turn is electrochemically oxidized to $\mathrm{Fe}(\mathrm{III})$. The electro-oxidation of sulphydryl compounds (n-acetylcysteine and l-cysteine) was mediated

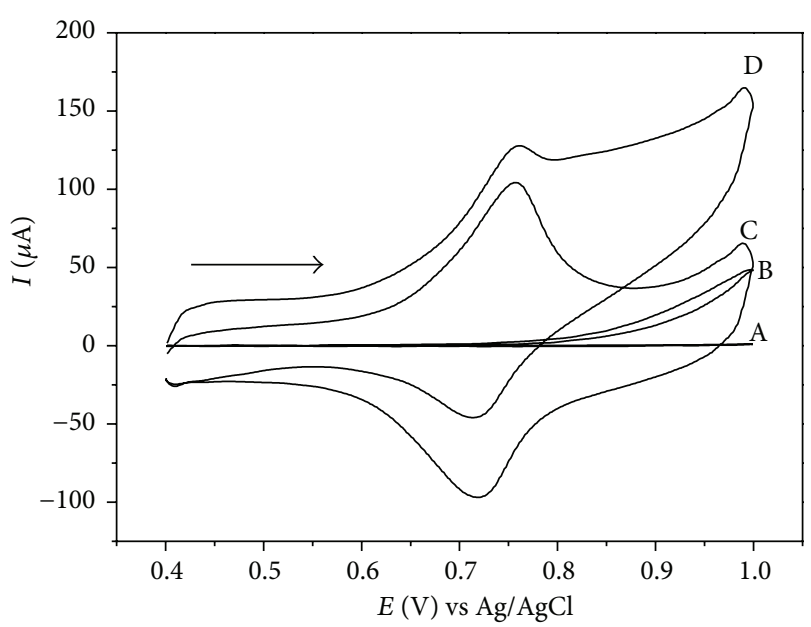

FIGURE 8: Cyclic voltammograms (A) of the graphite paste electrode; (B) of the graphite paste electrode and $1.0 \times 10^{-2} \mathrm{~mol} \mathrm{~L}^{-1}$ of $1-$ cysteine; (C) of the graphite paste electrode modified with CuHSA; and (D) of the graphite paste electrode modified with CuHSA in 1.0 $\times 10^{-2} \mathrm{~mol} \mathrm{~L}^{-1}$ of l-cysteine $\left(\mathrm{KCl} 1.0 \mathrm{~mol} \mathrm{~L}^{-1} ; v=20 \mathrm{mV} \mathrm{s}^{-1} ; \mathrm{pH} 7.0\right.$; $20 \%(w / w))$.

for ferricyanide (mediator) and occurs for an EC mechanism, where $\mathrm{E}$ is the electrochemical step and $\mathrm{C}$ is the chemical step.

Therefore, in view of this l-cysteine reaction, the oxidation of n-acetylcysteine on the electrode surface of the graphite paste electrode modified with CuHSA can be described by the following reactions:

$$
\begin{aligned}
& 2 \square \mathrm{K}_{2} \mathrm{Cu}^{\mathrm{II}}\left[\mathrm{Fe}^{\mathrm{II}}(\mathrm{CN})_{6}\right] \rightleftarrows 2 \square \mathrm{KCu}^{\mathrm{II}}\left[\mathrm{Fe}^{\mathrm{III}}(\mathrm{CN})_{6}\right]+2 \mathrm{~K}^{+}+2 \mathrm{e}^{-}(0.76 \mathrm{~V}) \quad \mathbf{E} \\
& 2 \square \mathrm{KCu}^{\mathrm{II}}\left[\mathrm{Fe}^{\mathrm{III}}(\mathrm{CN})_{6}\right]+2 \mathrm{X}+2 \mathrm{~K}^{+} \rightleftarrows 2 \square \mathrm{K}_{2} \mathrm{Cu}^{\mathrm{II}}\left[\mathrm{Fe}^{\mathrm{II}}(\mathrm{CN})_{6}\right]+\mathrm{Y}+2 \mathrm{H}^{+} \quad \mathrm{C}
\end{aligned}
$$

where $\mathrm{X}=\mathrm{n}$-acetylcysteine (or 1 -cysteine) and $\mathrm{Y}$ is $=\mathrm{n}$ acetylcysteine (or cystine).

Thus, n-acetylcysteine and l-cysteine are oxidized at the electrode surface, and this process occurs at the potential of $0.78 \mathrm{~V}$ and $0.76 \mathrm{~V}$, respectively. The oxidation process does not occur in this potential when employing glassy carbon electrode or unmodified graphite paste electrode.

The electrochemical behavior of the oxidation of $n$ acetylcysteine in the electrode modified with CuHSA differs from the electrode modified with Prussian blue film, in which there is as a current increase in both oxidation potentials $(0.79$ and $0.95 \mathrm{~V})$ when in the presence of $\mathrm{n}$-acetylcysteine (1.0 $\mathrm{mol} \mathrm{L}^{-1}, \mathrm{KCl}, \mathrm{pH} 3.5$ versus $\left.\mathrm{Ag} / \mathrm{AgCl}\right)$ [61].

However, the Prussian blue film [61] is degraded by the hydrolysis reaction in solutions with higher $\mathrm{pH}$ values than five, which does not occur with CuHSA.

It was observed that the catalytic current of $\mathrm{n}$ acetylcysteine and 1-cysteine in this electrode (CuHSA) decreases over time after the first cycle, probably due to depletion [60] near the electrode surface or due to the fact that the electrode response is blocked by the product resulting from the reaction [62].

Figures 9 and 10 illustrate the analytical curves of the $\mathrm{n}$-acetylcysteine and 1 -cysteine concentration as a function of the anodic current. For n-acetylcysteine the modified electrode showed a linear region in the concentration range of 2 to $20 \mathrm{mmol} \mathrm{L}^{-1}$, with an equation corresponding to $\Delta \mathrm{Y}$ $(\mu \mathrm{A})=21.20+633.40$ [n-acetylcysteine] with a correlation coefficient of 0.996 . The method showed a detection limit of $2.0 \times 10^{-3} \mathrm{~mol} \mathrm{~L}^{-1}$ with an amperometric sensitivity of $633.40 \mu \mathrm{A} / \mathrm{mol} \mathrm{L}^{-1}$ for $\mathrm{n}$-acetylcysteine.

For l-cysteine the modified electrode also showed a linear region in the concentration range of 2 to $20 \mathrm{mmol} \mathrm{L}^{-1}$ with an equation corresponding to $\Delta \mathrm{Y}(\mu \mathrm{A})=8.83+1751.25$ [1-cysteine] with a correlation coefficient of 0.999 and 


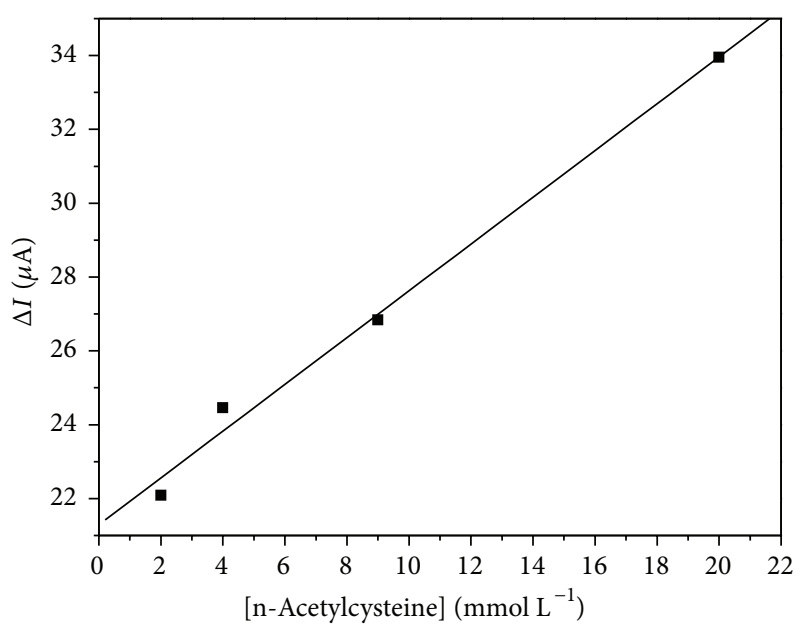

FIGURE 9: Analytical curve of the anodic peak for determination of n-acetylcysteine using the graphite paste electrode modified with CuHSA (KCl $1.0 \mathrm{~mol} \mathrm{~L}^{-1} ; v=20 \mathrm{mV} \mathrm{s}^{-1} ; \mathrm{pH} \mathrm{7.0;20 \% (w/w)).}$

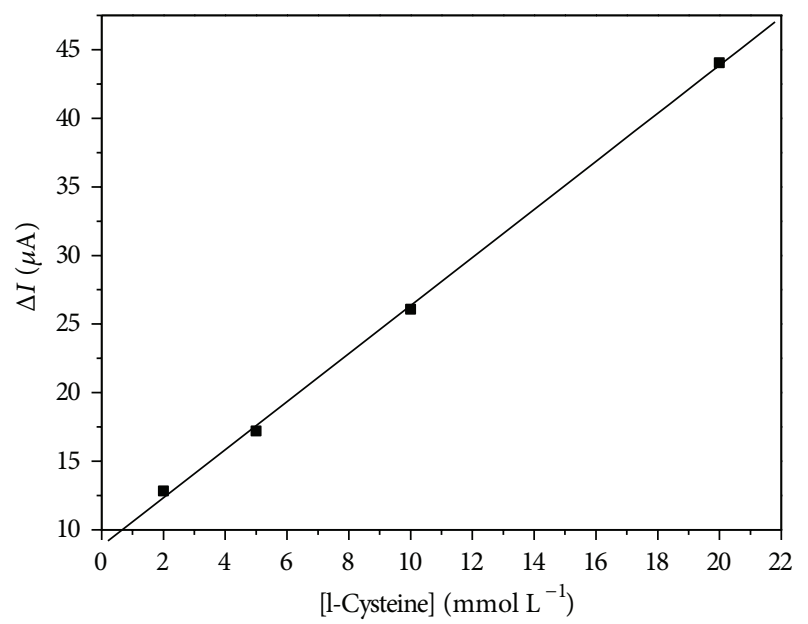

Figure 10: Analytical curve of the anodic peak for determination of l-cysteine using the graphite paste electrode modified with CuHSA $\left(\mathrm{KCl} 1.0 \mathrm{~mol} \mathrm{~L}^{-1} ; v=20 \mathrm{mV} \mathrm{s}^{-1} ; \mathrm{pH} 7.0 ; 20 \%(\mathrm{w} / \mathrm{w})\right.$ ).

a detection limit also of $8.55 \times 10^{-4} \mathrm{~mol} \mathrm{~L}^{-1}$ and an amperometric sensitivity of $1751.25 \mu \mathrm{A} / \mathrm{mol} \mathrm{L}^{-1}$.

\section{Conclusions}

The functionalization of octakis(3-Chloropropyl)silsesquioxane with 4-amino-5-(4-pyridyl)-4H-1,2,4-triazole-3-thiol was successfully carried out. The studies of FTIR and complementary studies of NMR in the solid state, together with SEM, confirm the nanostructured nature of organofunctionalized silsesquioxane.

The thermogravimetric analysis studies showed that this new material (SA) showed relative thermal stability up to temperatures of around $250^{\circ} \mathrm{C}$. After reaction of SA with $\mathrm{Cu}^{2+}$ and potassium hexacyanoferrate (III), the product formed (CuHSA) exhibit one redox couple with $E^{\theta^{\prime}}=0.75 \mathrm{~V}$. The redox couple presents a catalytic property for determination of sulfhydryl compounds. Quantitation in millimolar range of n-acetylcysteine and l-cysteine can be achieved using CuHSA incorporated in carbon paste electrode. An electrode surface renewal is not necessary as only a simple electrode is enough before each experiment. The electrode is chemically and electrochemically stable. This nanostructured material could be employed as starting reagent for synthesis of hybrid compounds.

\section{Conflict of Interests}

The authors declare that there is no conflict of interests regarding the publication of this paper.

\section{Acknowledgments}

Financial support for this research was supplied by Fundação de Amparo à Pesquisa do Estado de São Paulo (FAPESPGrant nos. 2012/05438-1, 2003/12882-6, and 2012/11306-0) and Conselho Nacional de Desenvolvimento Científico e Tecnológico (CNPq) Grant no. 306087/2012-0.

\section{References}

[1] P. Yin, Y. Tian, Z. Wang et al., "Synthesis of functionalized silica gel with poly(diethylenetriamine bis(methylene phosphonic acid)) and its adsorption properties of transition metal ions," Materials Chemistry and Physics, vol. 129, no. 1-2, pp. 168-175, 2011.

[2] U. Dittmar, B. J. Hendan, U. Flörke, and H. C. Marsmann, "Funktionalisierte octa-(propylsilsesquioxane) $\left(3-\mathrm{XC}_{3} \mathrm{H}_{6}\right) 8\left(\mathrm{Si}_{8}\right.$. $\mathrm{O}_{12}$ ) modellverbindungen für oberflächenmodifizierte kieselgele," Journal of Organometallic Chemistry, vol. 489, no. 1-2, pp. 185-194, 1995.

[3] R. H. Baney, M. Itoh, A. Sakakibara, and T. Suzuki, "Silsesquioxanes," Chemical Reviews, vol. 95, no. 5, pp. 1409-1430, 1995.

[4] D. B. Cordes, P. D. Lickiss, and F. Rataboul, "Recent developments in the chemistry of cubic polyhedral oligosilsesquioxanes," Chemical Reviews, vol. 110, no. 4, pp. 2081-2173, 2010.

[5] A. N. B. Bilyachenko, M. S. Dronova, A. I. Yalymov et al., "Binuclear cage-like copper(II) silsesquioxane ("Cooling Tower") its high catalytic activity in the oxidation of benzene and alcohols," European Journal of Inorganic Chemistry, vol. 2013, pp. 5240-5246, 2013.

[6] Y. Li, J. Wang, Y. Wu, H. Zhu, P. P. Samuel, and H. W. Roesky, "Synthesis of metallasiloxanes of group 13-15 and their application in catalysis," Dalton Transactions, vol. 42, no. 37, pp. 13715-13722, 2013.

[7] E. Biaecka-Florjańczyk and J. T. Sołtysiak, "Synthesis and characterization of liquid crystalline silsesquioxanes containing azobenzene groups," Molecular Crystals and Liquid Crystals, vol. 548, pp. 28-36, 2011.

[8] G. H. Mehl and I. M. Saez, "Polyhedral liquid crystal silsesquioxanes," Applied Organometallic Chemistry, vol. 13, no. 4, pp. 261-272, 1999.

[9] H. MacIejewski, M. Dutkiewicz, Ł. Byczyński, and B. Marciniec, "Silsesquioxanes as nanofillers-part I: silicone matrix nanocomposites," Polimery Warsaw, vol. 57, no. 7-8, pp. 535$544,2012$. 
[10] F. Du, Y. Bao, B. Liu, J. Tian, Q. Li, and R. Bai, "POSS-containing red fluorescent nanoparticles for rapid detection of aqueous fluoride ions," Chemical Communications, vol. 49, no. 41, pp. 4631-4633, 2013.

[11] X. Shen, Y. Cui, Y. Pang, and H. Qian, "Graphene oxide nanoribbon and polyhedral oligomeric silsesquioxane assembled composite frameworks for pre-concentrating and electrochemical sensing of 1-hydroxypyrene," Electrochimica Acta, vol. 59, pp. 9199, 2012.

[12] F. J. Feher, D. A. Newman, and J. F. Walzer, "Silsesquioxanes as models for silica surfaces," Journal of the American Chemical Society, vol. 111, no. 5, pp. 1741-1748, 1989.

[13] M. Handke and A. Kowalewska, "Siloxane and silsesquioxane molecules-precursors for silicate materials," Spectrochimica Acta A: Molecular and Biomolecular Spectroscopy, vol. 79, no. 4, pp. 749-757, 2011.

[14] M. Yao, J. Wang, X. Gu, and L. Feng, "Synthesis and application of dendrimers based on polyhedral oligomeric silsesquioxanes," Progress in Chemistry, vol. 24, no. 2, pp. 405-413, 2012.

[15] H. Ghanbari, B. G. Cousins, and A. M. Seifalian, "A nanocage for nanomedicine: polyhedral oligomeric silsesquioxane (POSS)," Macromolecular Rapid Communications, vol. 32, no. 14, pp. 1032-1046, 2011.

[16] D. R. do Carmo, L. L. Paim, N. L. Dias Filho, and N. R. Stradiotto, "Preparation, characterization and application of a nanostructured composite: octakis(cyanopropyldimethylsiloxy)octasilsesquioxane," Applied Surface Science, vol. 253, no. 7, pp. 3683-3689, 2007.

[17] D. Gnanasekaran, K. Madhavpan, and R. S. R. Reddy, "Developments of polyhedral oligomeric silsesquioxanes (POSS), POSS nanocomposites and their applications: a review," Journal of Scientific and Industrial Research, vol. 68, no. 6, pp. 437-464, 2009.

[18] K. Tanaka and Y. Chujo, "Advanced functional materials based on polyhedral oligomeric silsesquioxane (POSS)," Journal of Materials Chemistry, vol. 22, no. 5, pp. 1733-1746, 2012.

[19] S.-W. Kuo and F.-C. Chang, "POSS related polymer nanocomposites," Progress in Polymer Science, vol. 36, no. 12, pp. 16491696, 2011.

[20] D. Xu, L. S. Loo, and K. Wang, "Characterization and diffusion behavior of chitosan-poss composite membranes," Journal of Applied Polymer Science, vol. 122, no. 1, pp. 427-435, 2011.

[21] T. W. Dijkstra, R. Duchateau, R. A. van Santen, A. Meetsma, and G. P. A. Yap, "Silsesquioxane models for geminal silica surface silanol sites. A spectroscopic investigation of different types of silanols," Journal of the American Chemical Society, vol. 124, no. 33, pp. 9856-9864, 2002.

[22] G. Gerritsen, R. Duchateau, R. A. van Santen, and G. P. A. Yap, "Boron, aluminum, and gallium silsesquioxane compounds, homogeneous models for group 13 element-containing silicates and zeolites," Organometallics, vol. 22, no. 1, pp. 100-110, 2003.

[23] F. J. Feher and T. A. Budzichowski, "Silasesquioxanes as ligands in inorganic and organometallic chemistry," Polyhedron, vol. 14, no. 22, pp. 3239-3253, 1995.

[24] V. Lorenz, A. Fischer, and F. T. Edelmann, "Silsesquioxane chemistry, 6. The first beryllium silsesquioxane: synthesis and structure of $\left[\mathrm{Cy}_{7} \mathrm{Si}_{7} \mathrm{O}_{12} \mathrm{BeLi}\right]_{2} \cdot 2 \mathrm{THF}$,' Inorganic Chemistry Communications, vol. 3, no. 6, pp. 292-295, 2000.

[25] R. V. S. Alfaya, Y. Gushikem, and A. A. S. Alfaya, "Npropylpyridinium chloride silsesquioxane polymer film on graphite: electrochemical study of a hexacyanoferrate (II) ion immobilized electrode for oxidation of ascorbic acid," Journal of the Brazilian Chemical Society, vol. 11, no. 3, pp. 281-285, 2000.

[26] T. F. S. da Silveira, D. R. Silvestrini, U. D. O. Bicalho, and D. R. do Carmo, "Voltammetric study of a cubic silsesquioxane organically modified with imidazole and their subsequent reaction with cadmium and hexacyanoferrate (III)," International Journal of Electrochemical Science, vol. 8, no. 1, pp. 872-886, 2013.

[27] L. A. Soares, T. F. S. da Silveira, D. R. Silvestrini, U. de Oliveira Bicalho, N. L. D. Filho, and D. R. do Carmo, "A new hybrid polyhedral cubic silsesquioxane chemically modified with 4-amino-5-(4-pyridyl)-4H-1,2,4-triazole-3-thiol (APTT) and copper hexacyanoferrate(III) for voltammetric determination of nitrite," International Journal of Electrochemical Science, vol. 8, no. 4, pp. 4654-4669, 2013.

[28] H. Chu, H. Yang, S. Huan, W. Lin, G. Shen, and R. Yu, "Adsorption of purpald SAMs on silver and gold electrodes: a Raman mapping study," Journal of Raman Spectroscopy, vol. 38, no. 3, pp. 295-300, 2007.

[29] T. R. Ralph, M. L. Hitchman, J. P. Millington, and F. C. Walsh, "The reduction of l-cystine in hydrochloric acid at mercury drop electrodes," Journal of Electroanalytical Chemistry, vol. 587, no. 1, pp. 31-41, 2006.

[30] C. M. P. Vaz, S. Crestana, S. A. Spinola Machado, L. H. Mazo, and L. A. Avaca, "Adsorption isotherms for atrazine on soils measured by differential pulse polarography," Electroanalysis, vol. 9, no. 12, pp. 956-958, 1997.

[31] N. K. Kristiansen, M. Frøshaug, K. T. Aune, G. Becher, and E. Lundanes, "Identification of halogenated compounds in chlorinated seawater and drinking water produced offshore using n-pentane extraction and open-loop stripping technique," Environmental Science and Technology, vol. 28, no. 9, pp. 16691673, 1994.

[32] K. Rogers and C. Gerlach, "Peer reviewed: environmental biosensors: a status report," Environmental Science \& Technology, vol. 30, pp. 486A-491A, 1996.

[33] D. Patrascu, I. David, V. David et al., "Selective voltammetric determination of electroactive neuromodulating species in biological samples using iron(II) phthalocyanine modified multiwall carbon nanotubes paste electrode," Sensors and Actuators B: Chemical, vol. 156, no. 2, pp. 731-736, 2011.

[34] H. Wan, F. Zhao, and B. Zeng, "Direct electrochemistry and voltammetric determination of midecamycin at a multi-walled carbon nanotube coated gold electrode," Colloids and Surfaces B: Biointerfaces, vol. 86, no. 1, pp. 247-250, 2011.

[35] F. W. Campbell and R. G. Compton, "The use of nanoparticles in electroanalysis: an updated review," Analytical and Bioanalytical Chemistry, vol. 396, no. 1, pp. 241-259, 2010.

[36] H. Mao, Y. Li, X. Liu et al., “The application of novel spindle-like polypyrrole hollow nanocapsules containing Pt nanoparticles in electrocatalysis oxidation of nicotinamide adenine dinucleotide (NADH)," Journal of Colloid and Interface Science, vol. 356, no. 2, pp. 757-762, 2011.

[37] A. Walcarius, "Template-directed porous electrodes in electroanalysis," Analytical and Bioanalytical Chemistry, vol. 396, no. 1, pp. 261-272, 2010.

[38] D. R. P. Egan, C. T. J. Low, and F. C. Walsh, "Electrodeposited nanostructured lead dioxide as a thin film electrode for a lightweight lead-acid battery," Journal of Power Sources, vol. 196, no. 13, pp. 5725-5730, 2011.

[39] S. Dong, X. Chen, L. Gu et al., "A biocompatible titanium nitride nanorods derived nanostructured electrode for biosensing and 
bioelectrochemical energy conversion," Biosensors and Bioelectronics, vol. 26, no. 10, pp. 4088-4094, 2011.

[40] T. R. Soreta, O. Y. F. Henry, and C. K. OóSullivan, "Electrode surface nanostructuring via nanoparticle electronucleation for signal enhancement in electrochemical genosensors," Biosensors and Bioelectronics, vol. 26, no. 9, pp. 3962-3966, 2011.

[41] L. A. Soares, T. F. S. Silveira, D. R. Silvestrini, U. O. Bicalho, and D. R. do Carmo, "Use of a silsesquioxane organically modified with 4-amino-5-(4-pyridyl)-4H-1, 2, 4-triazole-3-thiol (APTT) for adsorption of metal ions," International Journal of Chemistry, vol. 5, pp. 39-48, 2013.

[42] D. R. Do Carmo, R. M. da Silva, and N. R. Stradiotto, "Electrocatalytic and voltammetric determination of sulfhydryl compounds through iron nitroprusside modified graphite paste electrode," Journal of the Brazilian Chemical Society, vol. 14, no. 4, pp. 616-620, 2003.

[43] J. Chojnowski, W. Fortuniak, P. Rościszewski et al., "Polysilsesquioxanes and oligosilsesquioxanes substituted by alkylammonium salts as antibacterial biocides," Journal of Inorganic and Organometallic Polymers and Materials, vol. 16, no. 3, pp. 219230, 2006.

[44] C. Yuan and C. Hu, "Synthesis and characterization of cagelike octa( $\gamma$-chloropropyl) silsesquioxane," Chemical Journal on Internet, vol. 2, no. 5, pp. 20-26, 2000.

[45] M. Dutkiewicz, H. Maciejewski, and B. Marciniec, "Functionalization of polyhedral oligomeric silsesquioxane (POSS) via nucleophilic substitution," Synthesis, vol. 1, no. 12, pp. 20192024, 2009.

[46] B. Marciniec, M. Dutkiewicz, H. Maciejewski, and M. Kubicki, "New, effective method of synthesis and structural characterization of octakis(3-chloropropyl)octasilsesquioxane," Organometallics, vol. 27, no. 4, pp. 793-794, 2008.

[47] R. M. Costa, Estudo de materiais nanoestruturados baseados em silsesquioxanos organomodificados: síntese, caracterização, formação de complexos e sorção de íons metálicos [M.S. thesis], Departamento de Física e Química, Universidade Estadual Paulista "Júlio de Mesquita Filho", Ilha Solteira, Brazil, 2009.

[48] R. M. Silverstein and F. X. Welbster, Identificação Espectrométrica de Compostos Orgânicos, John Wiley \& Sons, New York, NY, USA, 2000.

[49] T. Hatakeyama and F. X. Quinn, Thermal Analysis: Fundamentals and Applications to Polymer Science, Wiley, Aulnay-sousBois, 1999.

[50] Z. Zhang, G. Liang, and T. Lu, "Synthesis and characterization of cage octa(aminopropylsilsesquioxane)," Journal of Applied Polymer Science, vol. 103, no. 4, pp. 2608-2614, 2007.

[51] D. R. Carmo, L. S. Guinesi, N. L. Dias Filho, and N. R. Stradiotto, "Thermolysis of octa (hydridodimethylsiloxyl) octasilsesquioxane in pyridine media and subsequent toluidine blue $\mathrm{O}$ adsorption," Applied Surface Science, vol. 235, no. 4, pp. 449-459, 2004.

[52] D. R. Carmo, N. L. Dias Filho, and N. R. Stradiotto, "Synthesis and preliminary characterization of Octakis(chloropropyldimethylsiloxy)octasilsesquioxane," Materials Research, vol. 7, pp. 499-504, 2004.

[53] L. H. Marcolino Junior, Eletrodos Voltamétricos e Amperométricos Para a Determinação de Espécies de Interesse Farmacêutico, Tese (Doutorado)—Centro de Ciências Exatas e de Tecnologia, Campinas, Brazil, 2007.

[54] A. C. Pereira, A. S. Santos, and L. T. Kubota, "Tendências em modificação de eletrodos amperométricos para aplicações eletroanalíticas," Química Nova, vol. 25, pp. 1012-1021, 2002.
[55] M. F. B. Souza, "Eletrodos quimicamente modificados aplicados à eletroanálise: uma breve abordagem," Química Nova, vol. 20, pp. 191-195, 1997.

[56] S. Gabriel Junior, Preparação, caracterização e aplicações eletroanalíticas de silsesquioxanos e dendrímeros modificados suportados na superfície da sílica gel [M.S. thesis], Departamento de Física e Química, Universidade Estadual Paulista "Júlio de Mesquita Filho", Ilha Solteira, Brazil, 2010.

[57] A. L. Bard and L. R. Faulkner, Electrochemical Methods: Fundamentals and Applications, John Wiley \& Sons, New York, NY, USA, 1980.

[58] D. K. Gosser Junior, Cyclic Voltammetry: Simulation and Analysis of Reaction Mechanisms, Wiley-VCH, New York, NY, USA, 1st edition, 1993.

[59] M. Ribani, C. B. G. Bottoli, C. H. Collins, I. C. S. F. Jardim, and L. F. C. Melo, "Validação em métodos cromatográficos e eletroforéticos," Química Nova, vol. 27, pp. 771-780, 2004.

[60] T. R. Ralph, M. L. Hitchman, J. P. Millington, and F. C. Walsh, "The electrochemistry of 1-cystine and 1-cysteine-part 1: thermodynamic and kinetic studies," Journal of Electroanalytical Chemistry, vol. 375, no. 1-2, pp. 1-15, 1994.

[61] W. Hou and E. Wang, "Liquid chromatography with electrocatalytic detection of cysteine, $\mathrm{N}$-acetylcysteine and glutathione by a prussian blue film-modified electrode," Journal of Electroanalytical Chemistry, vol. 316, no. 1-2, pp. 155-163, 1991.

[62] N. Spãtaru, B. V. Sarada, E. Popa, D. A. Tryk, and A. Fujishima, "Voltammetric determination of L-cysteine at conductive diamond electrodes," Analytical Chemistry, vol. 73, no. 3, pp. 514519, 2001. 

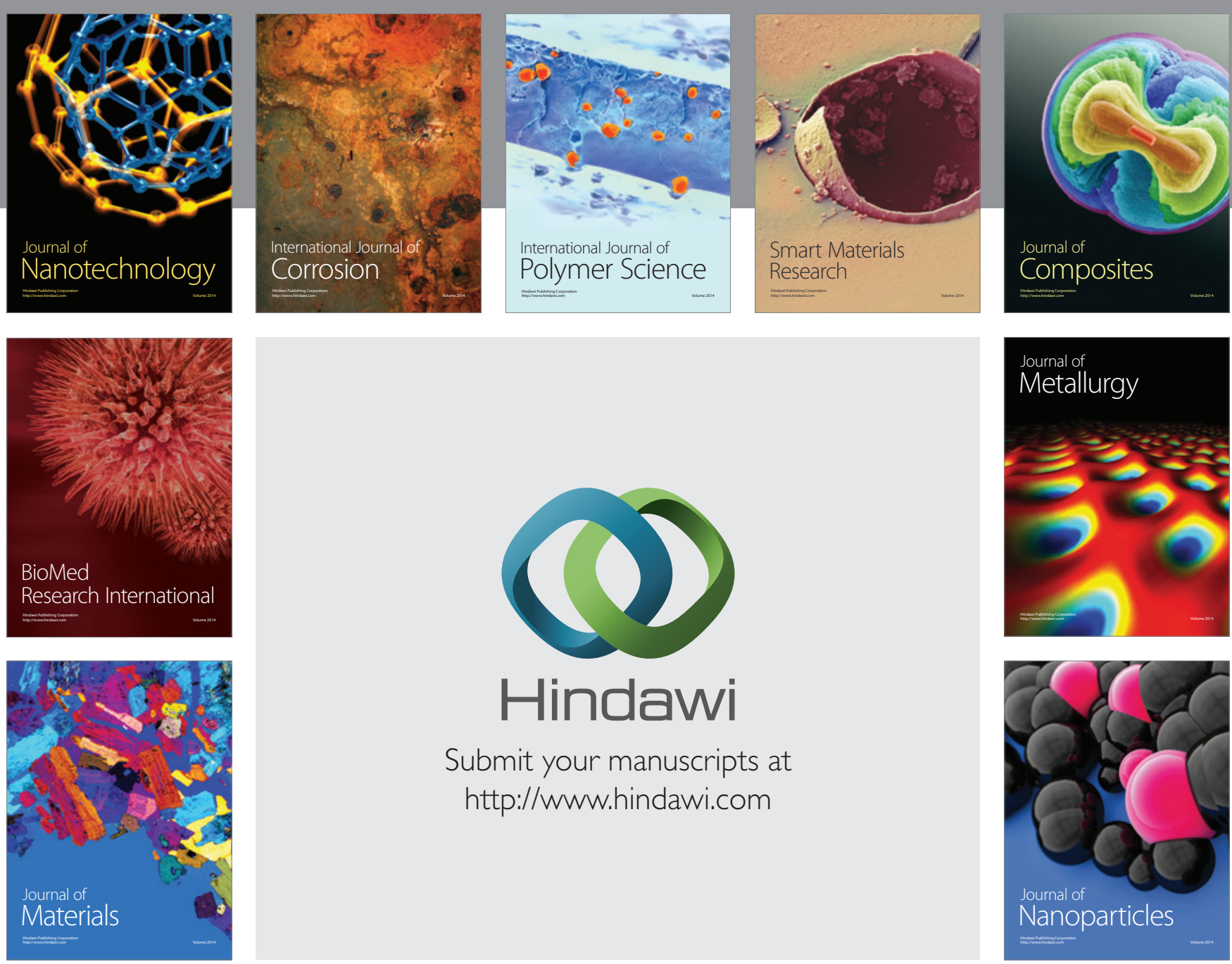

Submit your manuscripts at http://www.hindawi.com
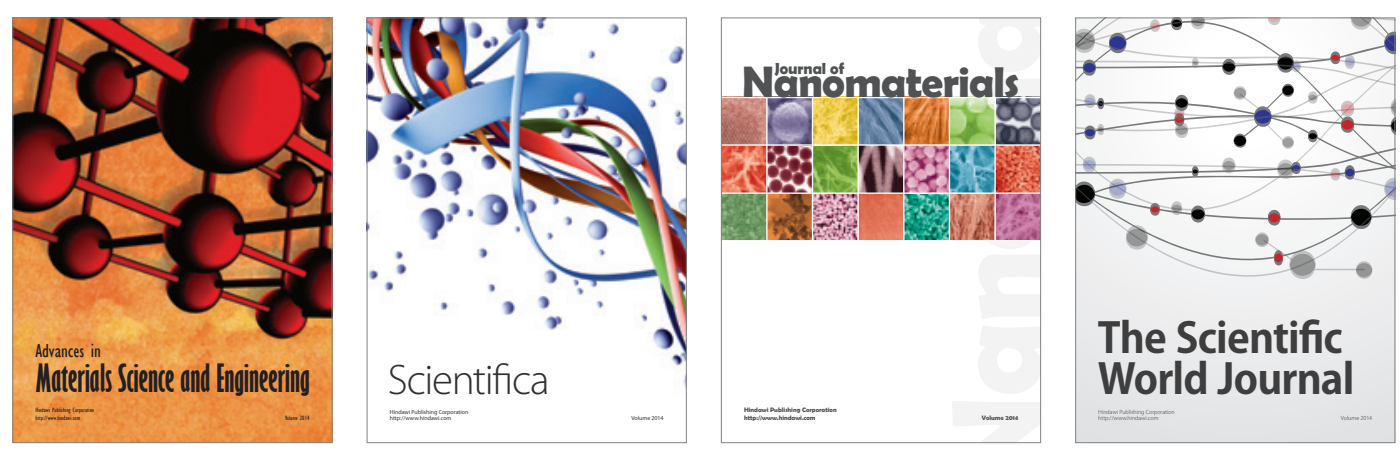

\section{The Scientific World Journal}
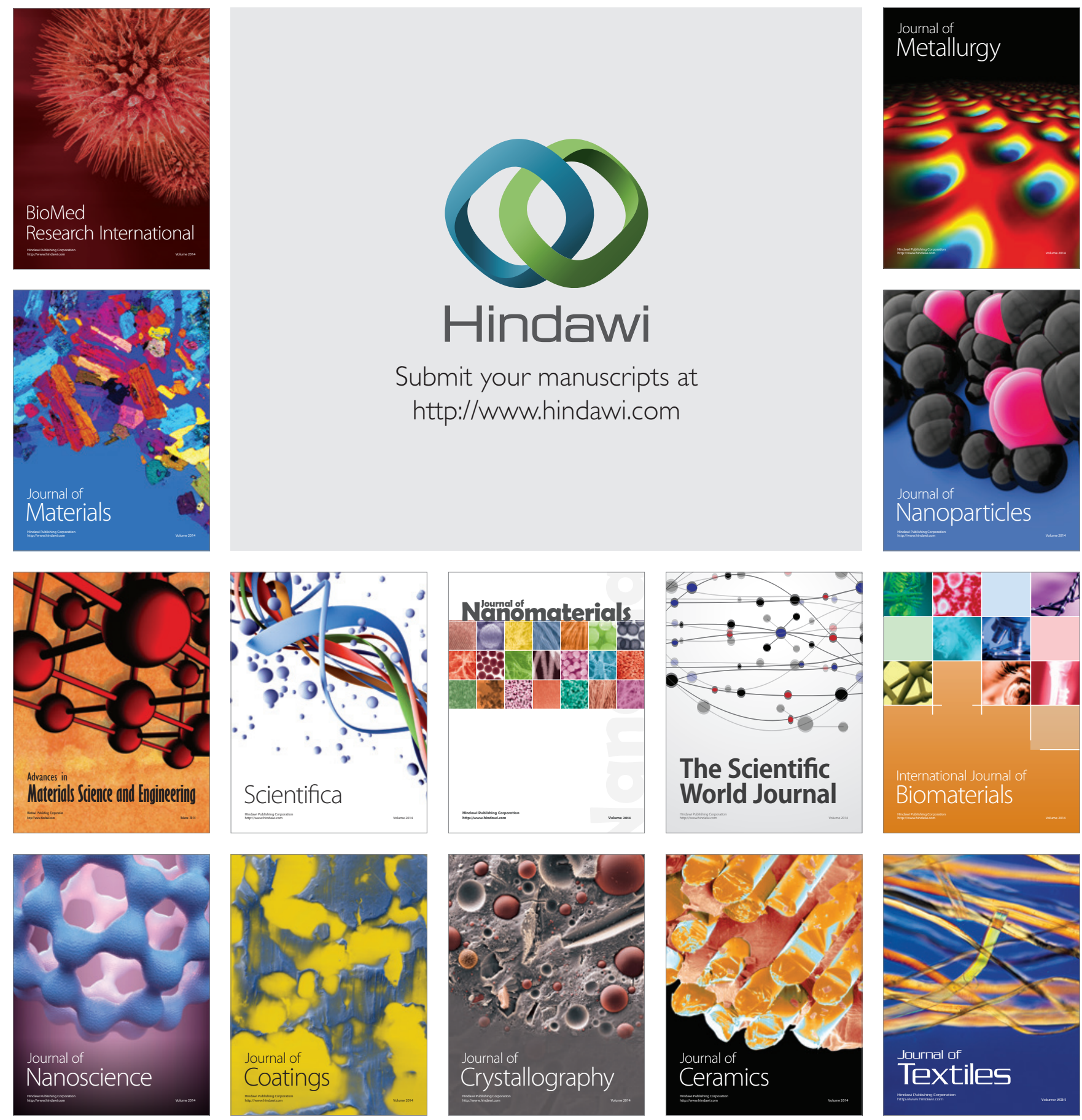